\title{
PREFERENSI MODALITAS BELAJAR VARK SISWA SEKOLAH DASAR KELAS III
}

\section{PREFERENCES OF VARK LEARNING MODALITIES GRADE III ELEMENTARY SCHOOL STUDENTS}

\author{
Kristophorus Divinanto Adi Yudono \\ Pendidikan Bahasa Indonesia Program Magister, Fakultas Bahasa dan Seni \\ Universitas Sanata Dharma \\ kristophorus3@gmail.com
}

\begin{abstract}
ABSTRAK
Kegiatan belajar yang tidak sesuai dengan gaya belajar siswa, dapat membawa dampak negatif bagi proses belajar siswa. Penelitian bertujuan untuk, (1) mendeskripsikan pola preferensi gaya belajar siswa, dan (2) memberikan rekomendasi kegiatan belajar yang sesuai dengan gaya belajar siswa. Penelitian dilakukan dengan pendekatan kualitatif deskriptif. Teknik pengumpulan data menggunakan kuesioner VARK 8.01 yang dimodifikasi agar sesuai untuk siswa sekolah dasar. Responden penelitian adalah 21 siswa kelas III yang terdiri dari 7 siswa laki-laki dan 14 siswa perempuan. Hasil penelitian menunjukkan bahwa terdapat beragam pola gaya belajar siswa, dengan 10 siswa bergaya belajar dominan visual [V], 5 siswa bergaya belajar dominan auditori [A], 1 siswa bergaya belajar dominan read/write [R], dan 1 siswa bergaya belajar dominan kinestetik [K]. Kelas III SD Pius Bakti Utama Kutoarjo didominasi siswa yang menyukai kegiatan belajar dengan melibatkan unsur penglihatan, seperti melihat gambar atau suatu tindakan. Meskipun demikian, guru perlu memfasilitasi seluruh gaya belajar siswa, dengan merancang kegiatan belajar yang sesuai dengan karakteristik gaya belajar visual, auditori, read/write, dan kinestetik. Kegiatan yang memfasilitasi seluruh gaya belajar dapat diterapkan pada pembelajaran tematik integratif.
\end{abstract}

Kata kunci: gaya belajar VARK, sekolah dasar, kegiatan belajar

Learning activities that do not fit the student's learning style, can have a negative impact on the student's learning process. The research aims to, (1) describe the pattern of preference of students' learning style, and (2) provide recommendations for learning activities that suit the student's learning style. The research was conducted with a descriptive qualitative approach. The data collection technique uses a modified VARK 8.01 questionnaire to suit elementary school students. The respondents to the study were 21 grade III students consisting of 7 male and 14 female students. The results showed that there were a variety of patterns of student learning styles, with 10 students in the visual dominant learning style [V], 5 students in the auditory dominant learning style [A], 1 student in the dominant learning style read/write [R], and 1 student in the dominant kinesthetic learning style [K]. Grade III SD Pius Bakti Utama Kutoarjo is dominated by students who love learning activities by involving elements of vision, such as seeing a picture or an action. However, teachers need to facilitate the entire learning style of students, by designing learning activities that match the characteristics of visual, auditory, read/write, and kinesthetic learning styles. Activities that facilitate the entire learning style can be applied to integrative thematic learning.

Keywords: VARK learning style, elementary school, learning activities 


\section{PENDAHULUAN}

Seorang pendidik dipersiapkan dengan berbagai kompetensi antara lain, kompetensi pedagogik, kompetensi kepribadian, kompetensi sosial dan kompetensi profesional. Masingmasing kompetensi memiliki perannya dalam mewujudkan visi misi keberhasilan sistem pendidikan. Setiap kompetensi dirinci kembali dalam bentuk sub kompetensi, yang perlu diperhatikan dan dikuasai oleh guru. Salah satu sub kompetensi yang terdapat pada kompetensi pedagogik adalah mengenali karakteristik dan potensi siswa [1]. Pemahaman guru terhadap karakteristik dan potensi siswa, termasuk pada pemahaman terhadap gaya belajar masing-masing siswa. Berbagai muatan pembelajaran di jenjang sekolah dasar disampaikan secara tematik, dengan muatan pembelajaran bahasa Indonesia sebagai penghela. Muatan pembelajaran bahasa Indonesia di tingkat sekolah dasar, berperan sebagai penghela atau dimaksudkan sebagai penyampai esensi substansi materi ajar, sedangkan muatan pembelajaran lain dijadikan sebagai konteks pelajaran Bahasa Indonesia yang diwujudkan dalam bentuk pembelajaran tematik integratif [2]. Kegiatan belajar bukan lagi mempelajari materi secara terpisah, melainkan menjadi satu kesatuan yang utuh. Setiap muatan pelajaran menyusun capaian-capaian ajar yang dikemas dalam bentuk tema dan subtema. Capaian-capaian ajar disusun dalam rumusan kompetensi inti. Rumusan kompetensi inti dipetakan dari Kompetensi Inti-1 (KI-1) untuk kompetensi inti sikap spiritual; Kompetensi Inti-2 (KI-2) untuk kompetensi inti sikap sosial; Kompetensi Inti-3 (KI-3) untuk kompetensi inti pengetahuan; dan Kompetensi Inti-4 (KI-4) untuk kompetensi inti keterampilan [3]. Masing-masing kompetensi tersebut dapat tercapai dengan adanya perhatian terhadap keberlangsungan kegiatan belajar, salah satunya adalah perhatian terhadap gaya belajar siswa.

Gaya belajar menjadi salah satu elemen penting di dalam kegiatan belajar mengajar termasuk pada jenjang sekolah dasar. Oxford mengungkapkan gaya belajar merupakan faktor utama yang membantu seseorang untuk mengetahui proses dan indikator penguasaan dalam pembelajaran [4]. Pengertian gaya belajar senantiasa lekat kaitannya dengan kegiatan belajar. Gaya belajar didefinisikan sebagai suatu proses memperoleh pengetahuan dan keterampilan baru [4]. Seiring berkembangnya zaman, teori gaya belajar berkembang dan memunculkan berbagai model gaya belajar. Model-model gaya belajar diungkapkan para ahli seperti Reid, Kolb, Gregorc, Felder-Silverman, Dunn \& Dunn, Entwistle dan Tait, hingga Flemming. Setiap siswa memiliki cara dalam proses kegiatan belajar yang berbeda antara siswa satu dengan siswa yang lain. Gaya belajar menjadi sarana adil dalam melihat masing-masing perbedaan siswa. Dalam praktiknya, membedakan siswa tampak adil dengan hasil belajar. Namun dibandingkan dengan hasil belajar, gaya belajar dapat digunakan untuk membedakan dan mengklasifikasikan perbedaan individu siswa secara adil [5]. Seorang siswa merasa tertarik pada suatu muatan pembelajaran, dengan adanya kesesuaian gaya belajar yang siswa miliki dengan substansi pembelajaran yang tengah dipelajari.

Gaya belajar yang dimiliki oleh siswa dapat pula digunakan untuk mengidentifikasi potensi yang siswa miliki tentang suatu bidang [6]. Siswa yang mengetahui gaya belajarnya, dimungkinkan untuk memperoleh pengetahuan secara optimal dengan menyesuaikan gaya belajar yang dimilikinya. Bagi guru yang mengetahui gaya belajar siswa, guru dapat memfasilitasi kebutuhan belajar setiap siswa, dengan mengemas pembelajaran yang sesuai dengan preferensi gaya belajar setiap siswa [7]. Berdasarkan uraian tersebut, dapat disimpulkan bahwa baik guru maupun siswa dirasa penting untuk memiliki pengetahuan mengenai gaya belajar sebagai upaya mewujudkan kegiatan belajar mengajar efektif, menciptakan hasil belajar optimal, dan mengembangkan potensi masing-masing siswa. Salah satu perspektif gaya belajar diungkapkan oleh Fleming yang mengungkapkan gaya belajar model VARK. Gaya belajar VARK merupakan gaya belajar pengembangan dari gaya belajar sebelumnya, yakni gaya belajar VAK. Fleming melakukan pembedaan indikator gaya belajar $[\mathrm{V}]$ atau visual, dengan memunculkan unsur baru dengan simbolisasi [R] atau yang dimaksud read/write [R] [4]. Gaya belajar VARK merupakan singkatan dari empat gaya belajar yang diungkapkan oleh Fleming. Empat huruf VARK mewakili masing-masing gaya belajar, yakni [V] untuk visual, [A] untuk auditori, [R] read/write, dan [K] 
untuk kinestetik [8]. Masing-masing alfabet mewakili satu gaya belajar yang memiliki karakternya dalam penerapan kegiatan belajar.

Perangkat yang digunakan untuk mengetahui gaya belajar seseorang adalah kuesioner VARK versi 8.01. Kuesioner tersebut digunakan untuk mengetahui preferensi gaya belajar seseorang serta kategorisasi seseorang tergolong satu gaya belajar (unimodal), dua gaya belajar (bimodal), tiga gaya belajar (trimodal), maupun empat gaya belajar (quadrimodal) [9]. Guru perlu mengakomodasi strategi belajar dengan menggunakan variasi metode belajar yang sesuai dengan masing-masing gaya belajar siswa. Pembelajaran yang hanya menggunakan satu metode yang sesuai untuk satu gaya belajar, dapat berpengaruh terhadap kegiatan belajar mengajar seperti menurunnya motivasi belajar siswa, rendahnya partisipasi di dalam kegiatan belajar mengajar, serta berpengaruh terhadap hasil belajar siswa [4]. Keterkaitan antara gaya belajar dengan pembelajaran membuat gaya belajar menjadi salah satu aspek penting untuk diketahui oleh pihak guru maupun siswa dalam upayanya mencapai tujuan pembelajaran secara optimal. Jumlah gaya belajar yang dimiliki siswa turut memberikan dampak terhadap proses kegiatan belajar. Seorang multimodal lebih mampu untuk beradaptasi terhadap guru maupun terhadap kegiatan pembelajaran yang diselenggarakan, dibanding dengan seorang unimodal [10]. Namun, jumlah gaya belajar bukan sebagai indikator kekuatan belajar, melainkan indikator kemampuan adaptasi siswa terhadap guru maupun beragam kegiatan pembelajaran.

Kajian ini bertujuan, (1) mendeskripsikan gaya belajar VARK siswa kelas III di SD Pius Bakti Utama Kutoarjo, dan (2) memberikan rekomendasi kegiatan belajar yang dapat memfasilitasi seluruh gaya belajar siswa. Peneliti berharap kajian dapat bermanfaat untuk guru sebagai menjadi refrensi untuk menganalisis gaya belajar siswa, dan sebagai salah satu pertimbangan dalam menyusun serta menyelenggarakan kegiatan belajar mengajar di hari selanjutnya. Deskripsi gaya belajar siswa kelas bukan hanya bermanfaat sebagai refrensi guru dalam kegiatan belajar mengajar, melainkan turut bermanfaat bagi orang tua siswa dalam mendampingi kegiatan belajar di rumah.

\section{METODOLOGI PENELITIAN}

Penelitian dilakukan dengan pendekatan kualitatif deskriptif. Pendekatan penelitian dipilih berdasarkan orientasi dari penelitian yakni mendeskripsikan gaya belajar VARK siswa kelas III SD Pius Bakti Utama Kutoarjo, serta memberikan saran kegiatan pembelajaran yang diselenggarakan berdasarkan gaya belajar tersebut, dalam bentuk narasi bahasa. Responden terdiri dari 21 siswa kelas III SD Pius Bakti Utama Kutoarjo, yang terdiri dari 7 siswa laki-laki dan 14 siswa perempuan. Lokasi penelitian dilakukan di SD Pius Bakti Utama Kutoarjo yang terletak pada Kabupaten Purworejo Provinsi Jawa Tengah. Data diperoleh melalui hasil kuesioner VARK yang diisi oleh seluruh siswa di kelas III. Peneliti melakukan modifikasi instrumen kuesioner VARK dengan mempertimbangkan kesesuaian kuesioner untuk digunakan siswa jenjang sekolah dasar.

Hasil dari instrumen VARK 8.01 tersebut merupakan gambaran dari pola gaya belajar VARK yang dimiliki oleh setiap siswa. Hal tersebut dapat memenuhi tujuan penelitian yang pertama, yakni mengetahui pola gaya belajar VARK siswa kelas III SD Pius Bakti Utama Kutoarjo. Setelah pola gaya belajar siswa diketahui, peneliti dapat memenuhi tujuan penelitian kedua, merekomendasikan penyelenggaraan kegiatan belajar yang memfasilitasi seluruh preferensi gaya belajar siswa di kelas III SD Pius Bakti Utama Kutoarjo. Analisis data dalam penelitian dilakukan dengan menggunakan teknik analisis data kualitatif interaktif Miles dan Huberman, yang terdiri dari empat tahap yaitu, pengumpulan data, reduksi data, penyajian data, dan penarikan kesimpulan atau verifikasi. Analisis dilakukan dengan mengidentifikasi tanggapan siswa, mengelompokkan sesuai dengan tipe gaya belajar VARK, menuliskan hasil identifikasi dalam bentuk tabel dan narasi bahasa, serta menarik kesimpulan. Langkah selanjutnya adalah memberikan rekomendasi kegiatan belajar yang sesuai dengan hasil analisis setiap gaya belajar siswa di kelas III SD Pius Bakti Utama Kutoarjo. 


\section{HASIL DAN PEMBAHASAN}

\section{Hasil Penelitian}

Pengisian instrumen VARK dilakukan pada tanggal 12 dan 13 Maret 2021. Berdasarkan hasil analisis instrumen, preferensi gaya belajar siswa kelas III di SD Pius Bakti Utama Kutoarjo terdiri dari, 10 siswa memiliki gaya belajar dominan visual [V], 5 siswa memiliki gaya belajar dominan auditori [A], 1 siswa memiliki gaya belajar dominan read/write [R], dan 5 siswa memiliki gaya belajar dominan kinestetik [K]. Terdapat siswa yang memiliki varian gaya belajar dan tidak memiliki varian belajar. Sejumlah 17 siswa memiliki lebih dari satu preferensi gaya belajar (multimodal), sedangkan 4 siswa memiliki preferensi gaya belajar tunggal (unimodal). Siswa kelas III di SD Pius Bakti Utama Kutoarjo didominasi siswa dengan empat gaya belajar (quadrimodal) yang memiliki persentase 38\%, dan didominasi oleh siswa dengan preferensi gaya belajar dominan visual [V] yang memilliki persentase $47 \%$. Data gaya belajar VARK siswa kelas III terdapat pada Tabel 1.

Tabel 1. Gaya Belajar VARK Siswa

\begin{tabular}{|c|c|c|c|c|}
\hline No & $\begin{array}{l}\text { Gaya Belajar } \\
\text { Dominan }\end{array}$ & Varian Gaya Belajar & $\begin{array}{c}\text { Kategori } \\
\text { Siswa }\end{array}$ & $\begin{array}{c}\text { Jumlah } \\
\text { Siswa }\end{array}$ \\
\hline 1 & Auditori $[\mathrm{A}]$ & $\begin{array}{c}\text { Visual [V], Kinestetik [K], } \\
\text { Read/write [R]. }\end{array}$ & Quadrimodal & 3 siswa \\
\hline 2 & Visual [V] & $\begin{array}{c}\text { Kinestetik [K], Read/write }[\mathrm{R}], \\
\text { Auditori }[\mathrm{A}]\end{array}$ & Quadrimodal & 1 siswa \\
\hline 3 & Visual [V] & $\begin{array}{l}\text { Read/write }[\mathrm{R}], \text { Auditori }[\mathrm{A}] \\
\text { Kinestetik [K]. }\end{array}$ & Quadrimodal & 1 siswa \\
\hline 4 & Visual [V] & $\begin{array}{c}\text { Auditori }[\mathrm{A}], \text { Read/write }[\mathrm{R}] \text {, } \\
\text { Kinestetik }[\mathrm{K}] .\end{array}$ & $\begin{array}{l}\text { Quadri } \\
\text { modal }\end{array}$ & 1 siswa \\
\hline 5 & Kinestetik $[\mathrm{K}]$ & $\begin{array}{c}\text { Visual [V], Auditori [A], Read/write } \\
\text { [R]. }\end{array}$ & $\begin{array}{l}\text { Quadri } \\
\text { modal }\end{array}$ & 1 siswa \\
\hline 6 & Visual [V] & $\begin{array}{c}\text { Kinestetik }[\mathrm{K}], \text { Auditori }[\mathrm{A}] \\
\text { Read/write }[\mathrm{R}] . \\
\end{array}$ & $\begin{array}{l}\text { Quadri } \\
\text { modal }\end{array}$ & 1 siswa \\
\hline 7 & Kinestetik $[\mathrm{K}]$ & $\begin{array}{c}\text { Read/write [R], Visual [V], Auditori } \\
{[\mathrm{A}] .}\end{array}$ & $\begin{array}{l}\text { Quadri } \\
\text { modal }\end{array}$ & 1 siswa \\
\hline 8 & Visual [V] & Auditori [A], Kinestetik [K]. & Trimodal & 1 siswa \\
\hline 9 & Visual [V] & Auditori [A], Read/write [R]. & Trimodal & 1 siswa \\
\hline 10 & Visual [V] & Kinestetik [K], Read/write [R]. & Trimodal & 1 siswa \\
\hline 11 & Auditori [A] & Kinestetik [K], Visual [V]. & Trimodal & 1 siswa \\
\hline 12 & Kinestetik [K] & Visual $[\mathrm{V}]$ & Bimodal & 1 siswa \\
\hline 13 & Read/write [R] & Auditori [A] & Bimodal & 1 siswa \\
\hline 14 & Visual [V] & Kinestetik [K] & Bimodal & 1 siswa \\
\hline 15 & Auditori $[\mathrm{A}]$ & Visual [V] & Bimodal & 1 siswa \\
\hline 16 & Kinestetik [K] & - & Unimodal & 2 siswa \\
\hline 17 & Visual [V] & - & Unimodal & 2 siswa \\
\hline & & Jumlah & & 21 siswa \\
\hline
\end{tabular}

\section{Pembahasan}

Persebaran data siswa laki-laki terdiri dari, 3 siswa dengan gaya belajar dominan visual [V], 1 siswa dengan gaya belajar dominan auditori [A], dan 3 siswa dengan gaya belajar dominan kinestetik $[\mathrm{K}]$. Tidak ada siswa laki-laki yang memiliki gaya belajar dominan read/write [R]. Persebaran data siswa perempuan terdiri dari, 7 siswa dengan gaya belajar dominan visual [V], 4 siswa dengan gaya belajar auditori [A], 1 siswa dengan gaya belajar read/write [R], dan 2 siswa dengan gaya belajar dominan kinestetik [K]. Sedangkan bagian pembahasan memaparkan hasil pengolahan data yang dilakukan dengan membandingkan / menguatkan hasil penelitian terdahulu. 
Jurnal Ilmiah KONTEKSTUAL, Volume.3, No..01, Agustus 2021, pp. 26-32

Usahakan untuk menampilkannya seringkas dan sekomprehensif mungkin menjawab masalah yang diangkat.

Berdasarkan data tersebut, dapat diketahui bahwa siswa di kelas III SD Pius Bakti Utama Kutoarjo lebih menyukai kegiatan belajar yang melibatkan unsur penglihatan, seperti melihat gambar atau mengamati kegiatan seseorang. Karakteristik gaya belajar visual yakni terdapat bukti-bukti konkret yang harus diperlihatkan terlebih dahulu kepada siswa agar siswa memahami substansi pembelajaran [11]. Siswa menyukai kegiatan belajar yang memanfaatkan indra penglihatan. Siwa dengan empat gaya belajar mendominasi kelas III dengan persentase angka $38 \%$, dibandingkan dengan siswa trimodal, bimodal, dan unimodal. Keberagaman pola preferensi gaya belajar siswa tersebut menunjukkan bahwa guru perlu mengakomodasi seluruh gaya belajar VARK yang terdiri dari visual, auditori, read/write, dan kinestetik.

Dominasi gaya belajar visual [V] pada siswa sekolah dasar turut ditemukan pada penelitian sebelumnya. Penelitian Juliani dkk berjudul "Analisis Gaya Belajar Siswa dalam Pembelajaran Bahasa Indonesia pada Siswa Kelas V SD Gugus VI Kecamatan Abang Kabupaten Karangasem Tahun Pelajaran 2015/2016", mengungkapkan bahwa gaya belajar visual [V] mendominasi siswa kelas VI di SD Gugus VI Kecamatan Abang Kabupaten Karangasem [12]. Dua hasil penemuan ini menunjukkan bahwa kecenderungan siswa sekolah dasar menyukai kegiatan belajar yang diselenggarakan dengan aspek visual [V].

Keberhasilan siswa dalam belajar dipengaruhi oleh beberapa faktor penunjang, salah satunya adalah pemahaman mengenai modalitas belajar atau gaya belajar. Pengetahuan guru terhadap gaya belajar siswa, menjadi salah satu bentu kompetensi pedagogik yang perlu dikuasai oleh guru. Memahami gaya belajar siswa merupakan wujud dari kompetensi guru dalam mengenali karakteristik dan potensi yang dimiliki siswa [13]. Selain itu, gaya belajar juga merupakan salah satu faktor internal yang mempengaruhi keaktifan peserta didik saat belajar [14]. Pembelajaran yang hanya menggunakan satu metode yang sesuai untuk satu gaya belajar, dapat berpengaruh terhadap kegiatan belajar mengajar seperti menurunnya motivasi belajar siswa, rendahny a partisipasi di dalam kegiatan belajar mengajar, serta berpengaruh terhadap hasil belajar siswa [4]. Keterkaitan antara gaya belajar dengan pembelajaran membuat gaya belajar menjadi salah satu aspek penting untuk diketahui oleh pihak guru maupun siswa dalam upayanya mencapai tujuan pembelajaran secara optimal. Jumlah gaya belajar yang dimiliki siswa turut memberikan dampak terhadap proses kegiatan belajar. Seorang multimodal lebih mampu untuk beradaptasi terhadap guru maupun terhadap kegiatan pembelajaran yang diselenggarakan, dibanding dengan seorang unimodal [10]. Namun, jumlah gaya belajar bukan sebagai indikator kekuatan belajar, melainkan indikator kemampuan adaptasi siswa terhadap guru maupun beragam kegiatan pembelajaran.

Kegiatan belajar yang memfasilitasi siswa dengan gaya belajar visual [V], dilakukan dengan mengoptimalkan fungsi indra penglihatan dengan memanfaatkan aspek-aspek visual. Kegiatan belajar yang memanfaatkan aspek visual, antara lain menggunakan gambar untuk ditampilkan pada layar salindia, membawa media belajar dalam bentuk fisik ke dalam kelas, meminta siswa mengamati benda-benda yang ada di lingkungan sekitar, atau guru yang menunjukkan peragaan. Rekomendasi kegiatan belajar tersebut sejalan dengan karakteristik siswa dengan gaya belajar visual [V], yakni siswa belajar dengan adanya bukti-bukti konkret yang harus diperlihatkan terlebih dahulu kepada siswa agar siswa memahami substansi pembelajaran [11]. Kegiatan belajar semacam ini dapat terus diselenggarakan oleh guru di kelas III SD Pius Bakti Utama Kutoarjo, mengingat kelas ini didominasi oleh siswa dengan gaya belajar visual.

Kegiatan belajar yang memfasilitasi siswa dengan gaya belajar auditori [A], dilakukan dengan mengoptimalkan fungsi indra pendengaran dengan memanfaatkan aspek-aspek audio. Kegiatan belajar yang memanfaatkan aspek audio atau suara, antara lain melakukan diskusi lisan, tanya jawab lisan, serta guru menjelaskan materi secara lisan dan bercerita secara lisan. Rekomendasi kegiatan belajar tersebut sejalan dengan gaya belajar auditori [A], yakni siswa mengoptimalkan aktivitas mendengar [11]. Kegiatan belajar semacam ini dapat diselenggarakan oleh guru di kelas III SD Pius Bakti Utama Kutoarjo, untuk memfasilitasi siswa yang memiliki preferensi gaya belajar auditori. 
Kegiatan belajar yang memfasilitasi siswa dengan gaya belajar read/write [R], dilakukan dengan membaca dan kegiatan menulis, dengan cakupan kata, kalimat, paragraf atau wacana [4]. Kegiatan belajar yang dapat dilakukan untuk memfasilitasi gaya belajar read/write [R], antara lain membaca teks yang terdapat pada buku pembelajaran tematik, membaca teks yang terdapat pada buku-buku penunjang lainnya, membaca tulisan yang ada di lingkungan sekitar (brosur, iklan, spanduk, baliho), menulis catatan, menuliskan kembali isi cerita, atau menulis cerita. Kegiatan belajar dapat semacam ini diselenggarakan oleh guru di kelas III SD Pius Bakti Utama Kutoarjo, untuk memfasilitasi siswa yang memiliki preferensi gaya belajar read/write.

Kegiatan belajar yang memfasilitasi siswa dengan gaya belajar kinestetik [K], dilakukan dengan mengadakan kegiatan praktik atau kegiatan belajar yang menuntut adanya pengalaman langsung. Kegiatan belajar yang dapat dilakukan adalah melakukan praktik seperti melakukan pengukuran, membuat kerajinan tangan, atau mempraktikkan kegiatan tertentu. Rekomendasi kegiatan belajar tersebut sejalan dengan gaya belajar kinestetik $[\mathrm{K}]$, yakni siswa menyentuh sesuatu ketika proses pemerolehan informasi atau pengetahuan dalam kegiatan belajarnya [11]. Kegiatan belajar semacam ini dapat diselenggarakan oleh guru di kelas III SD Pius Bakti Utama Kutoarjo, untuk memfasilitasi siswa yang memiliki preferensi gaya belajar kinestetik. Seluruh preferensi gaya belajar tersebut, dapat dirancang dalam kegiatan pembelajaran tematik integratif, yang diterapkan di jenjang sekolah dasar.

\section{SIMPULAN}

Kesesuaian kegiatan belajar dengan gaya belajar yang dimiliki siswa, dapat berpengaruh terhadap proses kegiatan belajar yang diselenggarakan. Pemahaman guru terhadap gaya belajar siswa penting untuk diketahui sebagai penunjang kegiatan belajar. Kajian ini mengungkapkan terdapat keberagaman gaya belajar VARK pada siswa kelas III SD Pius Bakti Utama Kutoarjo, yang didominasi oleh siswa dengan gaya belajar dominan visual [V]. Selain itu, siswa kelas III terdiri dari siswa yang memiliki beragam jumlah gaya belajar, dimulai dari siswa dengan satu gaya belajar (unimodal), hingga siswa dengan empat gaya belajar (quadrimodal). Meskipun kelas III SD Pius Bakti Utama didominasi oleh siswa yang menyukai kegiatan belajar dengan memanfaatkan penglihatan, guru perlu memfasilitasi seluruh gaya belajar siswa. Setiap siswa yang memiliki gaya belajar dominan auditori, read/write, dan kinestetik perlu difasilitasi dengan beragam bentuk kegiatan belajar. Guru dapat memfasilitasi seluruh gaya belajar VARK yang dimiliki siswa dengan menerapkan kegiatan belajar yang sesuai dengan masing-masing gaya belajar. Implementasi setiap gaya belajar tersebut dapat dilakukan pada pembelajaran tematik integratif yang saat ini berlangsung pada jenjang sekolah dasar. Orang tua masing-masing siswa dapat melakukan pendampingan belajar ketika di rumah, dengan mempertimbangkan gaya belajar yang telah ditemukan. Rekomendasi terhadap kajian selanjutnya yakni, peneliti dapat melakukan kajian terkait perkembangan gaya belajar siswa sekolah dasar, kajian terhadap gaya belajar siswa kelas atas (kelas 4, kelas 5, atau kelas 6), atau melakukan komparasi antara gaya belajar siswa sekolah dasar kelas atas dan bawah.

\section{DAFTAR PUSTAKA}

[1] Kemdikbud, Peraturan Menteri Pendidikan dan Kebudayaan Republik Indonesia Nomor 22 Tahun 2020. 2020.

[2] U. Khair, "Pembelajaran Bahasa Indonesia dan Sastra (BASASTRA) di SD dan MI," ARRIAYAH: Jurnal Pendidikan Dasar, vol. 2, no. 1, p. 81, 2018, [Online]. Available: http://journal.iaincurup.ac.id/index.php/JPD/article/view/261.

[3] A. Suhendra, Implementasi Kurikulum 2013 dalam Pembelajaran SD/MI. Jakarta: Prenada Media Group, 2019.

[4] B. Widharyanto, "Gaya belajar model vark dan implementasinya di dalam pembelajaran 
keterampilan Berbahasa Indonesia," International Conference on Education, Language, and Arts, 2017, [Online]. Available: https://www.researchgate.net/publication/343190928_GAYA_BELAJAR_MODEL_VA RK_DAN_IMPLEMENTASINYA_DI_DALAM_PEMBELAJARAN_KETERAMPIL AN_BERBAHASA_INDONESIA.

[5] C. Scott, "The enduring appeal of 'learning styles," Australian Journal of Education, vol. 54, no. 1, pp. 5-17, 2010, [Online]. Available: https://journals.sagepub.com/doi/10.1177/000494411005400102.

[6] R. Zonash and I. Naqvi, "Personality traits and learning styles among students of mathematics, architecture, and fine arts," Journal of Behavioural Sciences, vol. 21, no. 1, pp. 92-108, 2011, [Online]. Available: http://pu.edu.pk/images/journal/doap/PDFFILES/V21_7.pdf.

[7] W. Pangesti, Pentingnya memahami gaya belajar. Jakarta, 2018.

[8] L. Robertson, T. Smellie, P. Wilson, and L. Cox, "Learning styles and fieldwork education : students ' perspectives," New Zealand Journal of Occupational Therapy, vol. 58, no. 1, pp. 36-40, 2011, [Online]. Available: https://search.informit.org/doi/10.3316/INFORMIT.909364510433552.

[9] M. B. Firmansyah, "Multimodal conception in learning," ISLLAC : Journal of Intensive Studies on Language, Literature, Art, and Culture, vol. 2, no. 1, pp. 40-44, 2018, [Online]. Available: http://journal2.um.ac.id/index.php/jisllac/article/view/4140/2271.

[10] N. D. Fleming and C. Bonwell, How Do I Learn Best? a Learner'S Guide To Improved Learning. New Zeland, 2019.

[11] S. K. Sreenidhi and H. Tay Chinyi, "Styles of learning based on the research of Fernald, Keller, Orton, Gillingham, Stillman , Montessori and Neil D Fleming," International Journal for Innovative Research in Multidisciplinary Field, vol. 3, no. 4, pp. 17-25, 2017, [Online]. Available: content/uploads/2017/04/201704003.pdf.

[12] N. W. Juliani, I. N. Murda, and I. W. Widiana, "Analisis gaya belajar siswa dalam pembelajaran bahasa Indonesia pada siswa kelas V SD Gugus VI Kecamatan Abang Kabupaten Karangasem tahun pelajaran 2015/2016," e-Journal PGSD Universitas Pendidikan Ganesha Jurusan PGSD V, vol. 4, no. 1, pp. 1-12, 2016, [Online]. Available: https://ejournal.undiksha.ac.id/index.php/JJPGSD/article/view/7494.

[13] R. A. Cabual, "Learning styles and preferred learning modalities in the new normal," OALib, vol. 8, no. 4, pp. 1-14, 2021, [Online]. Available: https://www.scirp.org/journal/paperinformation.aspx?paperid=108297.

[14] F. F. Payon, D. Andrian, and S. Mardikarini, "Faktor yang mempengaruhi keaktifan belajar peserta didik kelas III SD," Jurnal Ilmiah KONTEKSTUAL, vol. 2, no. 2, pp. 5360, 2021, [Online]. Available: http://jurnal.umus.ac.id/index.php/kontekstual/article/view/397. 